\title{
Cardiovascular Risk and Hypertensive Patients' Knowledge, Attitudes and Practices on Modifiable Risk Factors in Kinshasa, the Democratic Republic of the Congo
}

\author{
Kashala Badianyama Remy ${ }^{1}$, Lukanu Ngwala Philippe ${ }^{2,}$, , Lepira Bompeka François ${ }^{3}$, \\ Fina Lubaki Jean-Pierre ${ }^{2}$, Prosper Mukobelwa Lutala ${ }^{4}$ \\ ${ }^{1}$ Monkole Hospital, Kinshasa, Democratic Republic of the Congo \\ ${ }^{2}$ Department of Family Medicine and Primary Health Care, School of Medicine, Protestant University of Congo, Kinshasa, Democratic \\ Republic of the Congo \\ ${ }^{3}$ Nephrology Service, School of Medicine, Kinshasa University, Kinshasa, Democratic Republic of the Congo \\ ${ }^{4}$ Department of Family Medicine, School of Public Health \& Family Medicine, College of Medicine University of Malawi, Blantyre, Malawi
}

Email address:

Remykashala1@gmail.com (K. B. Remy), phlukanu@yahoo.fr (L. N. Philippe), jeanpierrefina@yahoo.fr (F. L. Jean-Pierre),

jolutprosper@yahoo.fr (P. M. Lutala), plutala@medcol.mv (P. M. Lutala)

${ }^{*}$ Corresponding author

To cite this article:

Kashala Badianyama Remy, Lukanu Ngwala Philippe, Lepira Bompeka François, Fina Lubaki Jean-Pierre, Prosper Mukobelwa Lutala. Cardiovascular Risk and Hypertensive Patients' Knowledge, Attitudes and Practices on Modifiable Risk Factors in Kinshasa, the Democratic Republic of the Congo. Journal of Family Medicine and Health Care. Vol. 7, No. 2, 2021, pp. 47-56. doi: 10.11648/j.jfmhc.20210702.14

Received: June 4, 2021; Accepted: June 21, 2021; Published: June 28, 2021

\begin{abstract}
Good practice on modifiable cardiovascular risk factors is based on good knowledge and a positive attitude. The study aims to assess cardiovascular risk and knowledge, attitudes and practices of hypertensive patients in Kinshasa on modifiable cardiovascular risk factors as well as their associated determinants. We conducted a cross-sectional study with 345 hypertensive patients followed at Monkole Hospital and at Saint-Joseph Hospital in the city of Kinshasa in the Democratic Republic of the Congo from September 2017 to February 2018. The participants were submitted to the WHO-Steps survey. Cardiovascular risk was assessed by the number of deleterious risk factors present in patients. Descriptive and inferential analyzes were performed. The statistical significance threshold was set at $\mathrm{p}<0.05$. The average age of the participants was $62.1 \pm 11.2$ years with a gender ratio of 1.1 in favor of women. In total, $61 \%, 56 \%$ and $60 \%$ of our respondents had, respectively, a low level of knowledge, a bad attitude and an insufficient practice on modifiable cardiovascular risk factors. Good knowledge was statistically significantly linked to education, the medical profession as a source of information, and employment. Only age $\geq 60$ years was significantly associated with the right attitude in our patients while good practice was linked to the level of education. The majority of participants (80.3\%) had a high cardiovascular risk. Poor knowledge (p: 0.032) and insufficient overall practice $(\mathrm{p}<0.001)$ were significantly associated with high cardiovascular risk. The present study showed that hypertension was associated with a high Cardiovascular risk underpinned by a low level of knowledge, a bad attitude and insufficient practice on modifiable cardiovascular risk factors. Therefore, education programs and strategies to positively influence attitudes and practices are essential to reduce the impact of cardiovascular disease and its risk factors in our environment.
\end{abstract}

Keywords: Hypertension, Modifiable Risk Factor, Knowledge, Practice, Attitude, Kinshasa, DRC

\section{Introduction}

Cardiovascular diseases top the list of mortality causes worldwide with a high prevalence of modifiable risk factors
[1]. It was noted that both rural and urban areas in low and middle-income countries are experiencing a rise of modifiable risk factors in the recent years. [2] Not only that Non-communicable diseases (NCDs) including cardiovascular disease, are the leading cause of death 
worldwide, they are becoming also a burden to both individuals and health system. [3, 4]

This rise is becoming more and more evident in Low and Middle income countries (LMICs) for diverse reasons such as poor collaboration and response, challenge in prioritizing allocation of resources between NCDs and pre-existing infectious diseases, [5] poor health delivery standards; [6] bias in health seeking behaviour with the most poor going for affordable, substandard services; [7] poor detection and management in rural areas compared to urban's, [8] lack of control measures of risk factors in place to control high salt and fat consumption and data showing effect of interventions on them despite of availability of evidence supporting their cost-effectiveness; [9] and lastly, late detection with treatment commonly not aligned to guidelines and medicines not affordable by most patients. [10] Furthermore, LMICs, including sub-Saharan Africa (SSA) including DRC, NCDs present few specific features which also explain its negative impact on health systems and even development prospects of these countries: firstly, they appear at a younger age compared to the age of onset in the western's, complications and even deaths are seen prematurely and they carry a high death toll. Further, Sub-Saharan Africa share some other characteristics such as poor diets, [11] inactivity, [12] high tobacco and alcohol use. $[13,14]$ Low and Middle Income Countries share as well a high burden of HIV, [15] in-door air pollution [16] and early undernutrition [17] which all together or in solo contribute to the rise of noncommunicable diseases.

Similar to other SSA countries, Congo is confronted with the emergence of CVD and associated risk factors responsible for high morbidity and mortality in both urban and rural areas. [5, 6] Among these risk factors, hypertension, of which the prevalence has been estimated at $30.9 \%$. It is the main cause of morbidity and mortality. [7-9] In Sub-Saharan Africa, very few studies have assessed the determinants of knowledge and the level of knowledge of CVD and associated risk factors to provide essential data for the development of prevention and management strategies. [10]

A study conducted in Ethiopia to assess knowledge and associated factors of blood pressure control among hypertensive patients at the chronic illness follow-up Clinic of the University of Gondar comprehensive-specialized hospital showed that the knowledge was quite low and was more likely high in females, literates, employees and those with a hypertensive family member. [18] Investigating Knowledge, Attitude and Practice towards Hypertension among Residences of Altalbab village, ELHassahisa locality, Gezira State, Sudan; Asmhan Abdelwhab SidAhmed Ali [19] found that had higher levels of knowledge (about risk factors, symptoms and signs, diagnosis, control and lifestyle) contrasting with a lower levels' knowledge of the definition of hypertension. There was also a poor attitude about hypertension, but mixed levels of practice (high in checking $\mathrm{BP}$ ), but low in lifestyle (diets and physical activity). Even though studies examining specifically issues of knowledge, attitude and practice regarding hypertension are scarce and they are inexistent in most places in Kinshasa.
It was important to carry out this study in Kinshasa to get first-hand information of hypertensive in-patients. However, knowledge and attitudes of patients have effect on the management of their sicknesses, consistence in the management as well as the impact on blood pressure control, morbidity and mortality rates of patients. [20] On the other side lack of knowledge can led to patient's anxiety, [21] inappropriate use of health services, and others complications such as stroke, heart failure, glaucoma, and renal failure. [22] Furthermore, attitude, practices and knowledge are dynamic concepts, they change with time and even in space. Thus, they need monitoring overtime, or specifically for each area.

We therefore conducted the present study to capture the knowledge, attitude and practices specificities of the hypertensive population followed in two hospitals; the Monkole Hospital and Saint Joseph Hospital (HSJ) in the city of Kinshasa; Kinshasa (DRC).

\section{Methods}

\subsection{Study Design}

This study was a cross sectional descriptive survey of adult patients admitted to two hospitals in Kinshasa, DR Congo for hypertension over a period of five months. The cross sectional design was deemed appropriate as the aim of the study was to give a snapshot of the knowledge, attitude and practices of these patients at a given point in time.

\subsection{Setting for the Study}

Our study was carried out at Monkole Hospital and at Saint Joseph Hospital (HSJ), two general referral hospitals for the Mont-Ngafula Health Zone and the Limete Health Zone; Kinshasa; DRC respectively, between September 01, 2017 to February 28, 2018. The two health zones organize primary and secondary level clinics in their breasts to manage and monitor hypertensive patients.

\subsection{Study Population and Sampling Strategy}

Our population was made of patients admitted at Monkole and St Joseph District Hospitals during the period of data collection.

\subsubsection{Inclusion and Exclusion Criteria}

We included in this study patients who have been followed-up in the two hospitals for at least 3 months, are 18 years old and above and have given their informed consent to participate in the study. Were excluded in this study, all critically ill as well as pregnant women patients.

\subsubsection{Recruitment and Sample Size}

We calculated the minimum sample size for the study using the Cochran formula.[23] Following assumptions guided the sample size calculation: standard deviation=1.96; $\mathrm{p}=$ proportion of hypertensive patients with good practice on $\mathrm{MCVRF}=0.5 ; \mathrm{q}=1-\mathrm{p}=0.5 ; \mathrm{i}=$ margin of error $=0.05$; assuming a non-response rate of $5 \%$ of participants, the sample size 
was rounded-up to 345 (from 322 before adjusting for nonresponses).

In practice, we selected only hypertensive patients in an odd position following their order of arrival to the clinic (for outpatients' participants) or order of beds in the ward (for inpatients' participants) until the total sample size was reached.

\subsection{Data Collection}

We conducted data collection using the WHO-Stepwise approach to chronic non-communicable disease surveillance

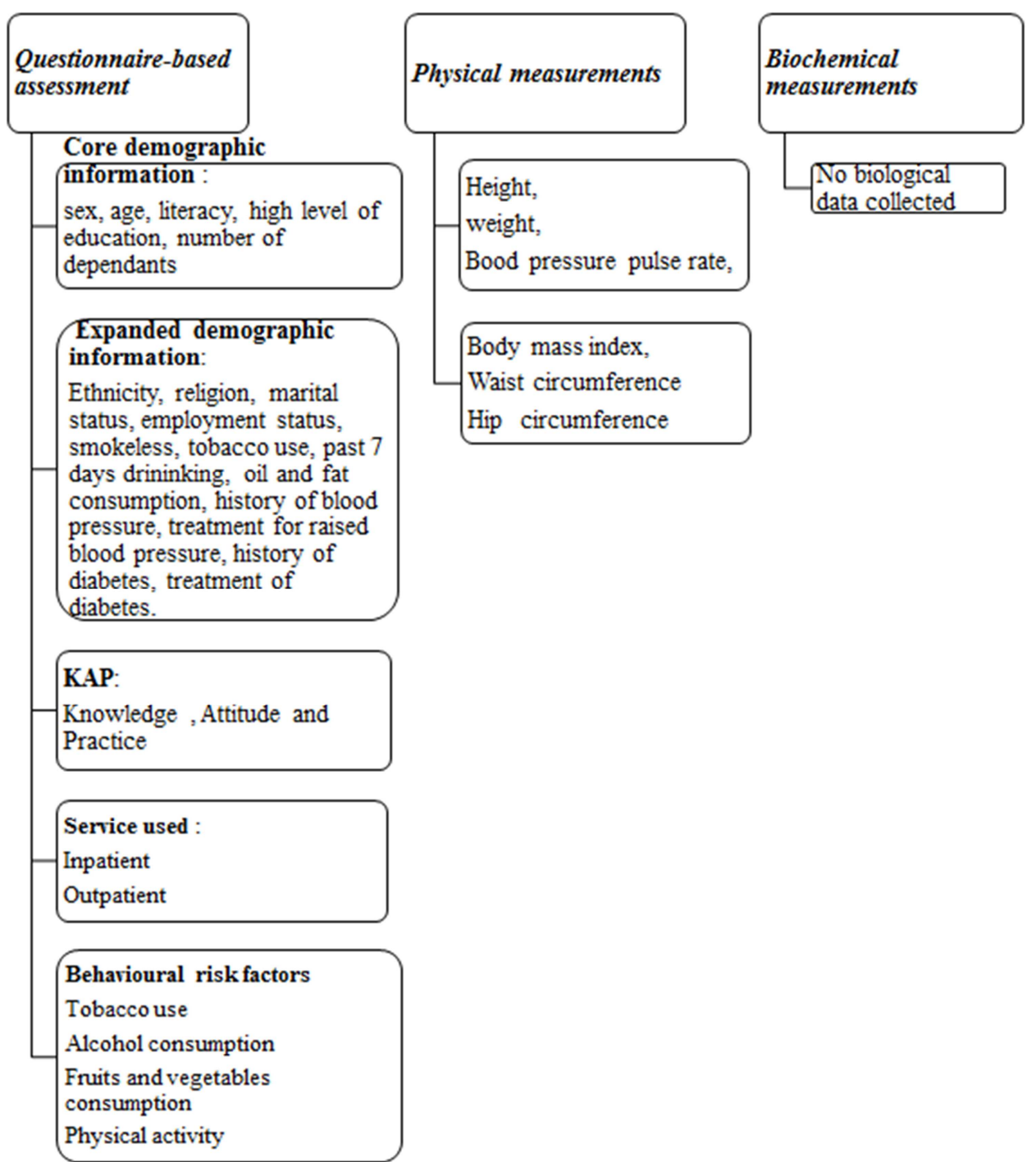

(WHO STEPS Survey). [24] The questionnaire was translated into Lingala (a widely spoken language in the setting) and adopted with minor modifications.

The figure 1 presents the informations of interest for our study; only the first two stages of the surveillance were used. The first stage involves a questionnaire-based assessment, and the second stage involves physical measurements on the patients.

Figure 1. Data collection process using STEP instrument for WHO Stepwise approach to surveillance.

Two medical doctors conducted data collection. After going through participation's information sheet and giving informed consent to participate, participant was asked questions related to their socio-demographic background, there after physical measurements were taken following Stepwise recommended procedures [24, 25].

Step 1. We collected demographic data (age, sex, profession, unemployment duration, education level, ethnic origin, marital status, religion, number of people in charge) of participants first, using a questionnaire form. They comprised core elements and expanded variable as portrayed in Figure 1. All behavioral risk factors (current exposure to tobacco and alcohol, diet and physical activity) were collected using The WHO Stepwise approach to Surveillance (STEPS) for NCD risk factors (current exposure to tobacco and alcohol, diet and physical activity). [24]

Step 2. The second step focused on anthropomorphic measurements: blood pressure, height, and weight, waist and hip circumferences. We used a digital blood pressure machine to collect blood pressure. For blood pressure 
measurements, a patient sat in the chair for 5 minutes before taking in the left forearm on a table in a supine position, palm facing the ceiling. The measurements were taken three times; and the mean of two last measurements we recorded. Blood pressure was taken using digital blood pressure machines (Automated Upper Arm Blood Pressure Monitor Scian LD-520, Scian). Weight measurements were taken with a bathroom scale on a barefoot patient wearing light clothes. The calibration of the scale was done on a daily basis to check for accuracy using a well-known weight reference (a pack of one kilograms of sugar). Measurements were taken to the nearest $0.1 \mathrm{~kg}$. The height was taken using a measurement attached on the wall, patient barefoot, in a strait position. The weight and height were then used to calculate the body mass index (BMI) as the weight in kilograms divided by the square of height in meters. Hip measurements were taken using a tape-measure placed horizontally at the point of maximum circumference over the buttocks. Waist circumference (WC) was measured using a tape-measure at the mid-axillary line midway between the last palpable rib and the superior iliac crest and Waist-to-hip ratio (ratio between waist circumference over hip circumference) calculated. All measurements height, weight on one hand, hip and waist measurements on the other were used to classify obesity in central and abdominal obesity, respectively.

The socio-demographic data were obtained using the WHO Steps questionnaire during the interviews; the anthropometric data were taken using a calibrated balance for weight, a wall height gauge for height, a measuring tape for the abdominal perimeter and, the BMI was calculated using the following formula Weight $(\mathrm{kg}) / \mathrm{Height}^{2}(\mathrm{~m})$. The ratio of weight (in kilograms) over the square of height (in meter) gave the body mass index (BMI). Values of BMI were grouped as follow: 19.5-25.9 normal weight, 25.5-29.9: overweight and equal or higher to 30 : obese. The wrist circumference cutoff values are for women $>87 \mathrm{~cm}$ and men $>90 \mathrm{~cm}$. Cardiovascular risk was assessed by the combination of the following factors: risky consumption of fruits and vegetables, excess alcohol, smoking tobacco and / or consuming non-smoked tobacco, excess salt, physical inactivity, consumption of animal fat, overweight or obesity, high blood pressure and stress. People at low risk had at most two factors, while those at high risk had at least three risk factors mentioned. The assessment of overall levels of knowledge, practice and attitude was carried out on the basis of a rating scale.

1. The overall knowledge score was calculated on a total of 10 points and evaluated in two scales as follows: scale of 0 to 3: poor knowledge and scale of 4-10: good knowledge: 4-10.

2. The attitude was appreciated by asking participants about their behavior in the face of high blood pressure readings; the overall attitude score was calculated on a total of 4 points: 0 to 2 and evaluated in two scales as follows: bad attitude and 3 to 4: good attitude.

3. The overall practice score was calculated on a total of 9 points and evaluated in two scales as follows: 0-3: insufficient overall practice, 4-9: sufficient overall practice.

\subsection{Data Analysis}

The data were entered on an excel sheet (Microsoft Excel 2010). And transferred to the Statistical Package for Socials Sciences (IBM SPSS Statistics 20) software for analysis. The quantitative continuous variables with Gaussian distribution were presented in the form of mean \pm standard deviation. The proportions and means were compared using the Chi-square test and Student's t-test, respectively. To determine association between knowledge, attitudes and practices with others variables, we used logistic regression in uni- and then multivariate analysis (with calculation of the Odds ratio and their $95 \%$ confidence intervals). For all the tests used, the threshold for statistical significance was set at $p<0.05$.

\subsection{Ethical Considerations}

All patients gave their informed consent before taking part in this study. We kept confidential all data at all stages by keeping raw data in a locked cabinet and then removing all identifiers at the late stage of analysis. The ethical clearance to conduct this study was granted by the University Protestant du committee (referenced CEUPC 0035).

\section{Results}

The study population consisted of 345 hypertensive patients, mostly women 182 women $(52.8 \%)$, with a gender ratio of 1.1. The mean age of the participants was $62.1 \pm 11.2$ years (extremes, SD); they were mostly outpatients $(91.3 \%)$, married (59.2\%), and unemployed (45.5\%).

Mean's values for duration of high blood pressure, body mass index (BMI), waist circumference, heart rate, systolic blood pressure (SBP), diastolic blood pressure (DBP), mean arterial pressure (MAP) and pulse pressure (PP) were $8.2 \pm 2.3$ years, $27.5 \pm 5.9 \mathrm{Kg} / \mathrm{m}^{2}, 98.6 \pm 13.6 \mathrm{~cm}$, respectively, $83.5 \pm 13.4$ pulses per minute, $144.8 \pm 22.4 \mathrm{mmHg}, 84.1 \pm 15.6$ $\mathrm{mmHg}, \quad 104.3 \pm 16.5 \mathrm{mmHg}$ and $60.7 \pm 16.0 \mathrm{mmHg}$, respectively. Obesity and diabetes mellitus (DM) were found in $25.8 \%$ and $31.6 \%$ of participants, respectively.

Slightly more than a third of participants $(38.6 \%)$ had a good knowledge of modifiable cardiovascular risk factors compared to $61.4 \%$ with a low knowledge. Age under 60 , male, divorced, employee, university level education and having more dependents were the main variables significantly associated with good knowledge of modifiable cardiovascular risk factors. (Table 1). in univariate analysis. In multivariate analysis, the strength of the associations observed in univariate analysis persisted only for the level of secondary or university education, employee status and information by the medical profession as factors significantly associated with good knowledge of the modified cardiovascular risk factors (Table 2). 


\subsection{Sociodemographic Characteristics of Participants}

Table 1. Socio-demographic characteristics of the participants by knowledge of the modifiable cardiovascular risk factors.

\begin{tabular}{|c|c|c|c|c|}
\hline & $\mathbf{N}$ & Faible connaissance $n=212$ (61.4) & Bonne Connaissance n=133 (38.6) & $\mathbf{P}$ \\
\hline Age, n (\%) & & & & $<0,001 * *$ \\
\hline$<60$ years old & 128 & $61(47,7)$ & $67(52,3)$ & \\
\hline$\geq 60$ years old & 217 & $150(69,1)$ & $66(30,4)$ & \\
\hline Sex, n (\%) & & & & $0,003 * *$ \\
\hline Males & 163 & $87(53,4)$ & $76(46,6)$ & \\
\hline Females & 182 & $125(68,3)$ & $57(31,7)$ & \\
\hline Service, n (\%) & & & & 0,575 \\
\hline Out-patients & 314 & $192(61,1)$ & $122(38,9)$ & \\
\hline In-patients & 31 & $19(61,3)$ & $11(35,4)$ & \\
\hline Marital status (\%) & & & & $<0,001 * *$ \\
\hline Married & 204 & $118(57,8)$ & $86(42,2)$ & \\
\hline Single & 44 & $22(50,0)$ & $22(50,0)$ & \\
\hline Separated & 14 & $4(28,6)$ & $10(71,4)$ & \\
\hline Widow/widower & 83 & $367(80,7)$ & $16(19,3)$ & \\
\hline Profession & & & & $<0,001 * *$ \\
\hline Private practice & 27 & $11(40,7)$ & $16(59,3)$ & \\
\hline Unemployed & 156 & $125(80,1)$ & $31(19,9)$ & \\
\hline Civil servant & 62 & $26(41,9)$ & $36(58,1)$ & \\
\hline Private compagny & 65 & $29(44,6)$ & $36(55,4)$ & \\
\hline Retired & 35 & $20(57,1)$ & $15(42,9)$ & \\
\hline Religion & & & & 0,981 \\
\hline Roman's Catholic & 184 & $113(61,4)$ & $71(38,6)$ & \\
\hline Protestant & 36 & $23(63,9)$ & $13(36,1)$ & \\
\hline Revival churches & 103 & $62(60,2)$ & $41(39,8)$ & \\
\hline Others & 22 & $13(59,1)$ & $9(40,9)$ & \\
\hline Education level attained & & & & $0,000 * *$ \\
\hline Primary & 82 & $74(90,2)$ & $8(9,8)$ & \\
\hline Secondary & 138 & $83(60,1)$ & $55(39,9)$ & \\
\hline Tertiary & 125 & $54(43,2)$ & $71(56,8)$ & \\
\hline \multicolumn{5}{|l|}{ Others } \\
\hline Years post-retirement & 33 & $10,3 \pm 3,6$ & $8,1 \pm 3,8$ & 0,490 \\
\hline Years of unemployement & 25 & $13,7 \pm 2,7$ & $8,4 \pm 2,7$ & 0,211 \\
\hline Number of dependants & 340 & $5,4 \pm 2,1$ & $7,1 \pm 2,7$ & $0,004 * *$ \\
\hline
\end{tabular}

**: difference highly significant; Data are expressed as mean \pm standard deviation, absolute frequency (n) and relative (in percent). Religion: others means: ....

\subsection{Determinants of Knowledge of Cardiovascular Modifiable Risk Factors of NCDs}

Table 2. Determinants of overall knowledge of cardiovascular modifiable risk factors.

\begin{tabular}{|c|c|c|c|c|}
\hline & \multicolumn{2}{|c|}{ Univariate Analysis } & \multicolumn{2}{|c|}{ Multivariate analysis } \\
\hline & $\mathbf{p}$ & ${ }^{\ddagger} \mathrm{COR}(95 \% \mathrm{CI})$ & $\mathbf{p}$ & ${ }^{\dagger}$ AOR $\left.95 \% \mathrm{CI}\right)$ \\
\hline \multicolumn{5}{|l|}{ Sex } \\
\hline Females & & 1 & & 1 \\
\hline Males & 0,005 & $1,89(1,21-2,93)$ & 0,212 & $1,47(0,80-2,71)$ \\
\hline \multicolumn{5}{|l|}{ Age, (in years) } \\
\hline$\geq 60$ & & 1 & & 1 \\
\hline$<60$ & $<0,001$ & $2,46(1,57-3,86)$ & 0,228 & $1,38(0,82-2,34)$ \\
\hline \multicolumn{5}{|c|}{ Education level attained } \\
\hline Primary & & 1 & & 1 \\
\hline Secondary & $<0,001$ & $6,13(2,74-13,71)$ & 0,002 & $3,98(1,66-9,56)$ \\
\hline Tertiary & $<0,001$ & $12,2(5,41-27,36)$ & 0,001 & $5,18(1,96-13,70)$ \\
\hline \multicolumn{5}{|l|}{ Profession } \\
\hline Unemployed & & 1 & & 1 \\
\hline Employed & $<0,001$ & $4,83(2,97-7,86)$ & $<0,001$ & $3,46(1,79-6,71)$ \\
\hline Number dependants & 0,006 & $1,85(1,02-2,15)$ & 0,067 & $1,04(0,99-1,09)$ \\
\hline \multicolumn{5}{|l|}{ Source of information } \\
\hline Others & & 1 & & 1 \\
\hline Heath professionals & $<0,001$ & $8,23(1,96-9,07)$ & $<0,001$ & $5,51(1,8-8,42)$ \\
\hline
\end{tabular}

${ }^{\ddagger}$ : crude odds ratio, ${ }^{\dagger}$ : adjusted odds ratio, and : $95 \%$ confidence interval. 


\subsection{Attitude of Participants Towards Modifiable Risk Factors and Their General Characteristics}

Forty-two percent of participants had a good attitude towards modifiable cardiovascular risk factors. Only age $\geq 60$ years was significantly associated with the right attitude $(\mathrm{p}=0.038)$ (Table 3$)$

Table 3. Association between the overall participant's attitude towards modified cardiovascular risk factors and their general characteristics.

\begin{tabular}{|c|c|c|c|c|}
\hline & $\mathbf{N}$ & Good attitude $n=152(44.1 \%)$ & Bad attitude $n=193(55.9 \%)$ & $\mathbf{p}$ \\
\hline Sex, n (\%) & & & & 0,388 \\
\hline Males & 163 & $70(42,9)$ & $93(57,1)$ & \\
\hline Females & 182 & $82(45,1)$ & $100(54,9)$ & \\
\hline Age, n (\%) & & & & $0,038^{*}$ \\
\hline$<60$ years old & 128 & $48(37,5)$ & $80(62,5)$ & \\
\hline$\geq 60$ years old & 217 & $104(47,9)$ & $113(52,1)$ & \\
\hline Marital status, n (\%) & & & & 0,250 \\
\hline Single & 44 & $17(38,6)$ & $27(61,4)$ & \\
\hline Divorced & 14 & $7(50,0)$ & $7(50,0)$ & \\
\hline Widow/widowed & 83 & $44(53,0)$ & $39(47,0)$ & \\
\hline Religion, n (\%) & & & & 0,154 \\
\hline Roman Catholic & 184 & $85(46,2)$ & $99(53,8)$ & \\
\hline Protestant & 36 & $10(27,8)$ & $26(72,2)$ & \\
\hline Rivival churches & 103 & $49(47,6)$ & $54(52,4)$ & \\
\hline Primary & 82 & $37(45,1)$ & $45(54,9)$ & \\
\hline Secondary & 138 & $61(44,2)$ & $77(55,8)$ & \\
\hline Tertiary & 125 & $54(43,2)$ & $71(56,8)$ & \\
\hline Profession, n (\%) & & & & 0,595 \\
\hline Private practice & 27 & $9(33,3)$ & $18(66,7)$ & \\
\hline Unemployed & 156 & $69(44,2)$ & $87(55,8)$ & \\
\hline Civil servant & 62 & $27(43,5)$ & $35(56,5)$ & \\
\hline Compagny employee & 65 & $28(43,1)$ & $37(56,9)$ & \\
\hline Retired & 35 & $19(54,3)$ & $16(45,7)$ & \\
\hline Years since retirement, (in years) & 33 & $10,1 \pm 3,6$ & $8,4 \pm 3,6$ & 0,598 \\
\hline Duration unemployement (in years) & 25 & $10,2 \pm 2,7$ & $13,3 \pm 2,4$ & 0,426 \\
\hline Number of dependants & 340 & $5,7 \pm 1,9$ & $6,4 \pm 1,4$ & 0,281 \\
\hline Knowledge about modifiable risk factors & 134 & $58(43,3)$ & $76(56,7)$ & 0,453 \\
\hline
\end{tabular}

Data are expressed as mean \pm standard deviation, absolute frequency (n) and relative (in percent). *: statistically significant.

Table 4. Association between overall practice on MCVRF and participant's basic characteristics.

\begin{tabular}{|c|c|c|c|c|}
\hline Variables & $\mathbf{N}$ & Nonsufficient practice $n=206(59.7 \%)$ & Sufficient practice $n=139(40.3 \%)$ & $\mathbf{p}$ \\
\hline Service, $\mathrm{n}(\%)$ & & & & 0,125 \\
\hline Ambulatoire & 314 & $184(58,6)$ & $130(41,4)$ & \\
\hline Hospitalisation & 31 & $22(71,0)$ & $9(29,0)$ & \\
\hline Sexe, n $(\%)$ & & & & $<0,001$ \\
\hline Male & 163 & $50(30,9)$ & $113(70,1)$ & \\
\hline Females & 182 & $156(81,5)$ & $26(19,5)$ & \\
\hline Age, n $(\%)$ & & & & 0,494 \\
\hline $34-60$ years & 128 & $77(60,2)$ & $51(39,8)$ & \\
\hline $60-88$ years & 217 & $129(59,4)$ & $88(40,6)$ & \\
\hline Marital states, n (\%) & & & & 0,785 \\
\hline Married & 208 & $120(58,8)$ & $84(41,2)$ & \\
\hline Single & 44 & $25(56,8)$ & $19(43,2)$ & \\
\hline Divorced & 14 & $10(71,4)$ & $4(28,6)$ & \\
\hline Widow/widowed & 83 & $51(61,4)$ & $32(38,6)$ & \\
\hline Religion, $\mathrm{n}(\%)$ & & & & 0,455 \\
\hline Roman Catholic & 184 & $116(63,0)$ & $68(37,0)$ & \\
\hline Protestant & 36 & $22(61,1)$ & $14(38,9)$ & \\
\hline Revival churches & 103 & $55(53,4)$ & $48(46,6)$ & \\
\hline Others & 22 & $13(59,1)$ & $9(40,9)$ & \\
\hline Education level attained. & & & & 0,032 \\
\hline Primary & 82 & $64(78,0)$ & $18(22,0)$ & \\
\hline Secondary & 138 & $88(63,8)$ & $50(36,2)$ & \\
\hline Tertiary & 125 & $54(43,2)$ & $71(56,8)$ & \\
\hline Employment & & & & $<0,001$ \\
\hline Yes & 189 & $80(42,3)$ & $109(57,7)$ & \\
\hline
\end{tabular}




\begin{tabular}{|c|c|c|c|c|}
\hline Variables & $\mathbf{N}$ & Nonsufficient practice $n=206(59.7 \%)$ & Sufficient practice $n=139(40.3 \%)$ & $\mathbf{p}$ \\
\hline No & 156 & $126(80,8)$ & $30(19,2)$ & \\
\hline Knowledge about modified CV risk & & & & 0,001 \\
\hline Yes & 134 & $60(23,7)$ & $74(76,3)$ & \\
\hline No & 211 & $146(69,1)$ & $65(30,9)$ & \\
\hline
\end{tabular}

Data are expressed as mean \pm standard deviation, frequency (n) and percentages.

\subsection{Association Between Practice on Modified Cardiovascular Risk Factors, Basic Characteristics and Level of Knowledge}

Sufficient practice was found in $40.3 \%$ of participants. In bivariate analysis, the proportion of participants with sufficient practice was significantly higher in men $(p<0.001)$, patients with tertiary level $(\mathrm{p}=0.032)$, working patients $(\mathrm{p}<0.001)$ and patients with knowledge of the modifiable cardiovascular risk factors $(\mathrm{p}=0.001)$ (Table 4$)$;

Table 5. Determinants of sufficient practice on the modified cardiovascular risk factors in the univariate and multivariate analysis of study population.

\begin{tabular}{|c|c|c|c|c|}
\hline \multirow{2}{*}{ Variables } & \multicolumn{2}{|c|}{ Univariate analysis } & \multicolumn{2}{|c|}{ Multivariate analysis } \\
\hline & $\mathbf{p}$ & $\operatorname{COR}(95 \% \mathrm{CI})$ & $\mathbf{p}$ & AORa (95\% CI) \\
\hline \multicolumn{5}{|l|}{ Sex } \\
\hline Females & & 1 & & 1 \\
\hline Males & $<0,001$ & $2,26(1,46-3,55)$ & 0,051 & $1,71(0,99-2,92)$ \\
\hline \multicolumn{5}{|l|}{ Education level attained } \\
\hline Primary & & 1 & & 1 \\
\hline Secondary & 0,051 & $1,77(0,99-3,13)$ & 0,296 & $1,38(0,75-2,53)$ \\
\hline \multicolumn{5}{|l|}{ Profession } \\
\hline Unemployed & & 1 & & 1 \\
\hline Employed & $<0,001$ & $2,44(1,57-3,79)$ & 0,074 & $1,76(0,95-3,27)$ \\
\hline \multicolumn{5}{|l|}{ Knowledge about modifiable CV } \\
\hline No & & 1 & & 1 \\
\hline Yes & 0,002 & $2,06(1,31-3,29)$ & $0,027 *$ & $1,77(1,07-2,95)$ \\
\hline
\end{tabular}

Table 6. Association between the level of cardiovascular risk, general characteristics, knowledge, attitude and their overall practice of participants on modifiable CV risk factors.

\begin{tabular}{|c|c|c|c|}
\hline Variables & High risk $n=68(19.7 \%)$ & Low risk $n=277(80.3 \%)$ & $\mathbf{p}$ \\
\hline Service, n (\%) & & & 0,412 \\
\hline Outpatients & $61(89,7)$ & $253(91,3)$ & \\
\hline Inpatients & $7(10,3)$ & $24(8,7)$ & \\
\hline Sex, n $(\%)$ & & & 0,260 \\
\hline Males & $35(51,5)$ & $128(46,2)$ & \\
\hline Females & $33(48,5)$ & $149(53,8)$ & \\
\hline Age ranges, $\mathrm{n}(\%)$ & & & 0,316 \\
\hline $60-88$ years old & $45(66,2)$ & $172(62,1)$ & \\
\hline Marital status, n (\%) & & & 0,530 \\
\hline Married & $43(63,2)$ & $161(58,1)$ & \\
\hline Single & $6(8,8)$ & $38(13,7)$ & \\
\hline Divorced & $4(5,9)$ & $10(3,6)$ & \\
\hline Widow/widowed & $15(22,1)$ & $68(24,5)$ & \\
\hline Religion, n (\%) & & & 0,340 \\
\hline Protestant & $10(14,7)$ & $26(9,4)$ & \\
\hline Revival churches & $22(32,4)$ & $81(29,2)$ & \\
\hline Others & $2(2,9)$ & $20(7,2)$ & \\
\hline Education level & & & 0,817 \\
\hline Primary & $15(22,1)$ & $67(24,2)$ & \\
\hline Secondary & $26(38,2)$ & $112(40,4)$ & \\
\hline Tertiary & $27(39,7)$ & $98(35,4)$ & \\
\hline Profession, n (\%) & & & 0,154 \\
\hline Employed & $33(48,5)$ & $156(56,3)$ & \\
\hline Unemployed & $35(51,5)$ & $121(43,7)$ & \\
\hline Knowledge about modifiable CV risk factors, n (\%) & & & $0,032 *$ \\
\hline Don't know & $20(29,4)$ & $191(69,0)$ & \\
\hline Know & $48(70,6)$ & $86(31,0)$ & \\
\hline Attitude, n (\%) & & & 0,279 \\
\hline
\end{tabular}




\begin{tabular}{llll}
\hline Variables & High risk n=68 (19.7\%) & Low risk n=277 (80.3\%) & p \\
\hline Good & $34(50,0)$ & $118(42,6)$ & \\
Bad & $34(50,0)$ & $159(57,4)$ & $<0,001^{* *}$ \\
Practice, n (\%) & & \\
Insufficient & $11(16,2)$ & $195(70,4)$ & \\
Sufficient & $57(83,8)$ & $82(29,6)$ & \\
\hline
\end{tabular}

Data are expressed as mean \pm standard deviation, absolute frequency (n) and relative (in percent).

\subsection{Determinants of Sufficient Practice of Modifiable Cardiovascular Risk Factors}

Multivariate analysis retained only the level of education and good knowledge of the MCVRF as associated determinants (Table 5), unlike in the univariates where all the 4 variables showed an association of $\operatorname{sex}(p=<0.001)$, tertiary education $(\mathrm{p}=0.008)$, employment $(\mathrm{p}<0.001)$, and knowledge about modifiable risk factors $(\mathrm{p}=0.002)$ with practice.

Table 6 Association between the level of cardiovascular risk of the patients in the study, their general characteristics, their knowledge, their attitude and their overall practice on MCVRF.

The vast majority of participants (80.3\%) had a high cardiovascular risk. Good knowledge (p: 0.032) and sufficient overall practice $(\mathrm{p}:<0.001)$ were significantly associated with low risk (Table 6).

\section{Discussion}

The vast majority of our participants had a high cardiovascular risk (80.3\%). In total, $61.2 \%, 56 \%$ and $60 \%$ of our respondents had, respectively, a low level of knowledge, a bad attitude and an insufficient practice on MCVRF. Level of secondary or university education, employee status and information by the medical profession were significantly associated with good knowledge of FRCVM. However, only age $\geq 60$ years was significantly associated with the right attitude $(\mathrm{p}=0.038)$. Sufficient practice was significantly higher in men, university-level patients, patients with professional activity and patients with knowledge of FRCVM

Our study found that $38.8 \%$ of hypertensive patients had a good knowledge of MCVRF against $61.2 \%$ with a low knowledge. Three studies, a Congolese, [26] a Nepalese [27] and a Nigerian [28] found similar results to ours. On the other hand, our results differ from those of two other studies conducted in Cameroon [29] and an Iran (30) where the participants reported, respectively, a good and average level of knowledge. This difference can be explained by the difference in the characteristics of our populations and by the definition of knowledge levels. Furthermore, in this study, good knowledge was significantly associated with the level of education, the source of information on cardiovascular risk factors and employment. A Beninese study retained the same variables as determinants of good knowledge; [31] however, in Iran, only education was noted as a determining factor. [30] While Benin and Congo share the same African, sub-Saharan blacks' characteristics in terms of sources of information (dominated by oral with high consideration of Witten's),
Iran's Asian's may be quite different due to business-oriented focus versus office's employment in Africa, less emphasize on education as a social norm for consideration rather than financial resources in Muslim's, Asian countries.

In the current study, $44.1 \%$ of participants showed a good attitude in the presence of high blood pressure figures. Our results align with those of Kamdem et al. in Cameroon. (29) Only age $\geq 60$ was associated with a good attitude.

Overall good practice was found in $40.3 \%$ of hypertensive patients compared with $59.7 \%$ with insufficient practice. Our results are similar to those of Vaidya in Nepal who found $48.8 \%$ of good practice towards cardiovascular diseases. [27] University education and good knowledge of MCVRF were associated with satisfactory practice. In Iran, Yaseen et al. found similar results. (30) The asymptomatic, silent clinical course of high blood pressure, and even hypertension distorts a bit its importance and may impact on the way participants were practicing with regard to the diseases.

After combining MCVRF, in this study, the high cardiovascular risk level was observed in $80.3 \%$ of hypertensive patients. Our results corroborate those of the studies carried out by Affangla et al. in Senegal [32] and by Longo et al. [33] in the DRC. However, in 2015, Munyapara et al. [34] have rather, found in Kinshasa a large deviation from our results, most probably due to the use of a different score. Our results showed that good knowledge and sufficient overall practice were significantly associated with low risk and corroborate those of Lima et al. in Brazil [35] and Yaseen et al. in Iran. [30]

Beyond the methodological limits, this study suggests that reducing cardiovascular risk requires a good knowledge of MCVRF and the implementation of recommendations in order to prevent them. Longitudinal studies, aimed at developing education and intervention strategies for the appropriation of prevention measures in communities, are recommended in the future.

This study has to be interpreted in light of some limitations:

1. Our questionnaire, although standardized, is intended for the general population. In our study, it was used for a particular population represented by hypertensive patients followed-up as outpatients.

2. The cross-sectional nature of our survey didn't allow us to establish cause-effect relationships between the variables of interest. However, the associations drawn from the current cross-sectional study could assist in initiating some robust designs such as cohort or randomized trials which could establish whether or not such a relation exists between variables of interest.

3. The following biases may have interfered with our data: (1) although the sampling method used 
guaranteed equal opportunity for each member of the study population to participate in the study, it would have been possible to have a sample that did not represent the population of interest (sampling bias). Nonetheless, without going through randomization, the current sample was enough to respond to our research question (s). (2) Bias linked to the investigator: systematic difference from how the interviewer solicits, records, or interprets information. To minimize this risk, we trained investigators and advised them to remain neutral all along the interviews; and finally (3) volunteering bias: as the selection in the study was made on a voluntary basis, the characteristics of the patients selected may differ from those of the non-participants.

\section{Conclusion}

The present study showed that hypertension was associated with a high $\mathrm{CV}$ risk underpinned by a low level of knowledge, a bad attitude and insufficient practice on modified cardiovascular risk factors. Education programs and strategies to positively influence attitudes and practices are essential to reduce the impact of cardiovascular disease and its risk factors in Kinshasa.

\section{References}

[1] Beaglehole R, Bonita R, Horton R et al. (2011) Priority actions for the non-communicable disease crisis. Lancet. 377 (9775): 1438-47.

[2] Carrillo-Larco RM, Miranda JJ, Li X et al.(2019) Prevalence ofpragmatically defined high CV risk and its correlates in LMIC: a report from 10 LMIC Areas in Africa, Asia, and South America. Glob Hear. 11 (1): 27-36.

[3] Truthmann J, Busch MA, Scheidt-Nave C et al. (2015) Modifiable cardiovascular risk factors in adults aged 40-79 years in Germany with and without prior coronary heart disease or stroke. BMC public Heal. 15: 701.

[4] Stewart J, Manmathan G WP. (2017) Primary prevention of cardiovascular disease: A review of contemporary guidance and literature. Cardiovascular Disease. J R Soc Med Cardiovasc Dis. 6: 1-9.

[5] Beaglehole R, Bonita R, Alleyne G, R H, Li L et al. (2005) UN High- Level Meeting on Non-Communicable Diseases: addressing four questions. Lancet. 2011; 378: 449-455.

[6] Opie L, Seedat Y. Hypertension in sub-Saharan African populations. Circulation. 112: 3562-3568.

[7] Suhrcke M, Boluarte TA, Niessen LA. (2012) A systematic review of economic evaluations of interventions to tackle cardiovascular disease in low- and middle-income countries. BMC Public Health. 12 (2).

[8] Opie LH SY. (2005) Hypertension in sub-Saharan African populations. Circulation. 112: 3562-3568.

[9] Van der Sande M, Coleman R, Schim van der Loeff, MF
McAdam K, Nyan OA et al. (2001) A template for improved prevention and control of cardiovascular disease in subSaharan Africa.. Heal Policy Plan. 16: 345-350.

[10] Hajar I, Kotchen J, Kotchen T.(2006) Hypertension: trends in prevalence, incidence, and control. Annu Rev Public Heal. 27: 465-490.

[11] Imamura F, Micha R, Khatibzadeh S, Et A.(2015) Dietary quality among men and women in 187 countries in 1990 and 2010: a systematic assessment. Lancet Glob Heal. 3: e132-42.

[12] Sallis J, Cerin E, Conway T, Et A. (2016) Physical activity in relation to urban environments in 14 cities worldwide: a crosssectional study. Lancet. 387: 2207-17.

[13] Forouzanfar M, Alexander L, HR A, Et A. (2015) Global, regional, and national comparative risk assessment of 79 behavioural, environmental and occupational, and metabolic risks or clusters of risks in 188 countries, 1990-2013: a systematic analysis for the global burden of disease study 2013. Lancet. 386: 2287-323.

[14] Lim S, Vos T, Flaxman A, Et A. (2012) A comparative risk assessment of burden of disease and injury attributable to 67 risk factors and risk factor clusters in 21 regions, 1990-2010: A systematic analysis for the global burden of disease study 2010. Lancet. 380: 2224-60.

[15] Currier J, Lundgren J, Carr A, Et A. (2008) Epidemiological evidence for cardiovascular disease in HIV-infected patients and relationship to highly active antiretroviral therapy. Circulation. 118: e29-35.

[16] Fullerton D, Bruce N, Gordon S. (2008) Indoor air pollution from biomass fuel smoke is a major health concern in the developing world. Trans R Soc Trop Med Hyg. 102: 843-51.

[17] Hult M, Tornhammar P, Ueda P, Et A. (2010) Hypertension, diabetes and overweight: looming legacies of the Biafran famine.; 5:. PLoS One. 5: e13582.

[18] Kassa Chilot M, Bezenaw Yimer M, Habtamu Sewinet M. (2019) Knowledge and Associated Factors of Blood Pressure Control Among Hypertensive Patients Attending Chronic Illness Follow-Up Clinic at University of Gondar, Comprehensive Specialized Hospital, Northwest, Ethiopia. Vasc Health Risk Manag. 15: 551-558.

[19] Ali AAS. (2017) Knowledge, Attitude and Practice towards Hypertension among Residences of Altalbab village, ELHassahisa locality, Gezira State, Sudan. University of Khartoum.

[20] Jimoh AK, Opadijo OG, Desalu OO, Olanrewaju TO, Busari OA, Agboola SM, et al.(2018) Knowledge, Attitude and Practices of Hypertension on Compliance with Antihypertensive Drugs in a Resource-poor Setting. TAF Prev Med Bull. 2018; 9 (2): 87-92.

[21] Sofia N, Hajira S, Muhammad A, Syed AG. (2018) Knowledge Attitude and Practice towards Hypertension among Adult Population in a Rural Area of Lahore, Pakistan. Int J Sci Eng Res. 9 (5).

[22] Osuala Eunice O.(2017) Hypertension Prevention and Control: Effects of a Community Health Nurse-led Intervention. J Heal Educ Res Dev. 5 (210): 2.

[23] Cochran W. (1977) Sampling techniques. 3rd ed. New York, NY: John Wiley \& Sons, Ltd; 10-20 p. 
[24] World Health Organization. (2005) WHO STEPS Surveillance Manual: The WHO STEPwise approach to chronic disease risk factor surveillance. Geneva, Switzerland: World Health Organization.

[25] $\mathrm{Ng} \mathrm{N}$, Van MH, Juvekar S, Razzaque A, Bich T, Kanungsukkasem U, et al.(2009) Using the INDEPTH HDSS to build capacity for chronic non-communicable disease risk factor surveillance in low and middle- income countries 1 , Glob Heal Action Suppl. 1.

[26] Katchunga P, Malanda B, Mwenze M, Et A.(2012) Connaissance de la population générale sur l'hypertension et le diabète sucré au Sud-Kivu, RDC. 60 (2): 141-7.

[27] Vaidya A, Aryal UR KA. (2013) Cardiovascular health knowledge, attitude and practice/behavior in an urbanizing community of Nepal. Bmj. 10 (3): e002976.

[28] Boateng D, Wekessah F, Browns J, Et A. (2017) Knowledge and awareness of and perception towards cardiovascular disease risk factors in sub-Saharan Africa: A systematic review.. PLoS One. 12 (12): e0189264.

[29] Kamdem F, Djomou F, Ngosala S, Et A. (2018) Connaissance des facteurs de risque cardiovasculaire et attitude de prévention par la population du district de la santé de DeidoCameroun. Heal Sci Dis. 19 (1).
[30] Yaseen R, Manaflouyan H, Nikniaz Z, Et A. (2018) Knowledge, attitude and practice of Iranian hypetensive patients ragarding hypertension. J Cardiovasc Thorac Res. 2018: 10 (1): 14-19. J Cardiovasc Thorac Res. 10 (1): 14-9.

[31] Cossi M, Preux P-M, Chabriat H, Gobron C, Et A.(2012) Knowledge of stroke among an urban population in Cotounou (Bénin). Neuro Epidemiol. 38 (3): 172-8.

[32] Affangla DA, Gueye C, Simo WA et al. (2016) Profil de risque cardiovasculaire du patient hypertendu en consultation externe au centre de prise en charge du diabète sucré et maladies métaboliques de l'hôpital St-Jean de Thiès.. Cardiol Trop. 146: 1.

[33] Longo M, Efini B, Nahimana D, Et A.(2006) Enquête sur les facteurs de risque des maladies non transmissibles à Kinshasa, capitale de la RD Congo, Selon l'Approche Steps OMS.

[34] Munyapara S, Mundu M, Kakudji I. Munyapara SA, Mundu MG, Kakudji IL.(2015) Evaluation du risque cardiovasculaire global des patients hypertendus suivis dans les centres médicaux militaires de Kinshasa, RDC. KisMed. 1: 117-23.

[35] Lima H, Gonçalve AR, Lewandowski da Silva A et al.(2015) The patient's knowledge about hypertension: an analysis based on cardiovascular risk. IJCS. 28 (3): 181-8. 